started an experimental farm with the object cf improving the most vital of all French industries. Dr. McKie describes the skill with which Lavoisier applied to farming the scientific analysis that marked all his researches and the great improvements in farming methods that he achieved.

When provincial assemblies were established in 1787, Lavoisier was elected a member of the assembly of Orléanais, and he was soon its outstanding figure. He saw so clearly the reforms that were long overdue: his memoranda on the corvée, on the state of agriculture, on old-age insurance, on savings banks and on the need for a geological survey show his modern outlook and his vision and imagination. Even in the dark days of the Revolution he never relaxed his efforts for France; in $\mathbf{1 7 9 3}$ he presented a report to the National Convention on national education, envisaging the complete democratization of opportunity with free primary education for all children. He foresaw, too, the need for science and industry to work together. "Much that he urged in the organization and application of science has been realised only in our own time."

Dr. McKie tells the sad story of the final tragedy, adding fresh evidence about a packet of letters "written in English" which might have contributed to Lavoisier's death. This book gives an admirably ba]anced story of Lavoisier's many-sided life. It is written with fullness of knowledge, with great sympathy and understanding, and has the lucidity that characterized the writings of Lavoisier himself. It is clearly destined to be a standard history of Lavoisier's unique record of intellectual and practical achievement.

H.AROLD H.ARTLEY

\section{BIRTH AND GROWTH OF EXPLOSIONS}

Initiation and Growth of Explosion in Liquids and Solids

By F. P. Bowden and A. D. Yoffe. (Cambridge Monographs on Physics.) Pp. xii $+104+5$ plates. (Cambridge: At the University Press, 1952.) 22s. 6d. net.

CREAT progress has been made during the past $\checkmark$ twenty years in the understanding of propagation of detonation in condensed explosives by the development of the hydrodynamic theory of detonation. This theory is purely mechanical, and like thermodynamics it has no curiosity, so that it tells us nothing about the nature of the decomposition or reaction of the explosive itself. It is all the more important, therefore, that collateral experimental work on the nature of the initiation and growth of explosion in condensed explosives should be prosecuted vigorously. Dr. F. P. Bowden and his school have carried out such work, first in Australia (with the then Cormmonwealth Council for Scientific and Industrial Research) during the Second World War and afterwards in Cambridge in the Research Laboratory on the Physics and Chemistry of Surfaces, and the results of the work are collected in the present monograph written by him in collaboration with Dr. A. D. Yoffe. Bowden's interest in explosives arose naturally from his work on the friction and lubrication of solids, which is described in a recent monograph written with Dr. D. Tabor as co-author (see Nature, 167,$252 ; 1951$ ). It was natural to utilize similar techniques for the study of the decomposition of explosives since these have always been tested by the now classical empirical tests involving impact and friction. Bowden and his school have, however, made a major advance in the understanding of the phenomena of the birth and growth of explosions in small quantities of material by demonstrating very elegantly that initiation is due to the formation of 'hot spots' of small but finite size in the explosive, and that such 'hot spots' are readily formed by adiabatic compression of minute gas-pockets trapped in the explosives. It is the essential simplicity of the disclosed mechanism which makes it such a valuable contribution.

The introductory chapter deals with the two principal theories of initiation of explosives by mechanical shock, namely, the tribochemical and thermal theories. As a result of their investigations, the authors favour the thermal theory and demonstrate that usually initiation is produced by the formation of a local 'hot spot'. Effective 'hot spots' can be produced in several ways; but the most important were found to be boundary friction between solid particles of high melting-point at points of rubbing contact, and adiabatic compression (and consequent heating) of minute gas or vapour bubbles in the explosive. The last chapter of the book deals with the growth and propagation of explosions from these minute 'hot spots'.

The book is illustrated with numerous photographs taken on rotating-drum cameras and showing the development of the explosion in various substances. In a considerable number of cases the 'hot spot' is succeeded by a phase of burning before detonation ensues, but in certain cases detonation ensues immediately after the 'hot spot'.

The book is readable and the arguments are readily followed; but it could have been more valuable to the specialist if more detailed and quantitative descriptions of the ingenious apparatus and methods used had been given. Nevertheless, the monograph is a very useful contribution to the literature and will be welcomed by both research workers and technicians in the explosives field. JAMES TAYLOR

\section{HEALTH EDUCATION TO-DAY}

\section{Health Education}

A Guide to Principles and Practice. By Cyril Bibby. (Heinemann Education Series.) Pp. $x+222$. (London: William Heinemann, Ltd., 1951.) 17s. 6d. net.

WHAT should be expected of health education Wo-day? Many valuable and useful manuals of hygiene exist giving us the facts of health and health education; but a well-considered account of the judgment of the present-day experienced experts on the principles and practice of health education has been wanted for some time. In this book Mr. Cyril Bibby has now written such an account, and many will be most rewarded by a first perusal and subsequent constant reference. To-day we have reached that point in health education where our principles must be put into practice (even if improvisation is still often required through lack of funds or resources), otherwise the facts of health which we offer to individuals in the communities of to-day will fail to produce any lasting or worth-while effect. This is a particularly salient comment for the teachers of the young of all age-groups; for sister tutors in the training schools; for the teachers of future medical 